\title{
FLT3 Tyrosine Kinase Inhibitor TTT-3002
}

National Cancer Institute

\section{Source}

National Cancer Institute. FLT3 Tyrosine Kinase Inhibitor TTT-3002. NCI Thesaurus.

Code C123362.

An orally bioavailable indolocarbazole derivative and inhibitor of constitutively active mutant forms of FMS-like tyrosine kinase 3 (FLT3) with potential antineoplastic activity. Following administration, FLT3 tyrosine kinase inhibitor TTT-3002 binds to and inhibits ligand-dependent dimerization and autophosphorylation of mutant forms of FLT3 with constitutively activating mutations, including FLT3 internal tandem duplication (FLT3/ITD) and the activating point mutation D835Y. Prevention of autophosphorylation inhibits uncontrolled FLT3 signaling and may result in the inhibition of proliferation in tumor cells expressing constitutively active mutant forms of FLT3. The ability of TTT-3002 to inhibit FLT3 proteins with activating point mutations may result in increased efficacy because the activity of these mutants are resistant to other FLT3 kinase inhibitors. FLT3, a tyrosine kinase receptor, plays a role in the regulation of hematopoietic progenitor cell proliferation, and in leukemic cell proliferation and survival. Constitutively activating mutations of FLT3 are the most frequent genetic alterations in acute myeloid leukemia. 